University of Montana

ScholarWorks at University of Montana

$1-2010$

\title{
Are forested buffers an effective conservation strategy for riparian fauna? An assessment using meta-analysis
}

\author{
Laurie B. Marczak \\ University of Montana - Missoula, laurie.marczak@cfc.umt.edu \\ Takashi Sakamaki \\ University of British Columbia \\ Shannon L. Turvey \\ University of British Columbia \\ Isabelle Deguise \\ University of British Columbia \\ Sylvia L. R. Wood \\ University of British Columbia \\ See next page for additional authors \\ Follow this and additional works at: https://scholarworks.umt.edu/biosci_pubs \\ Part of the Biology Commons \\ Let us know how access to this document benefits you.
}

\section{Recommended Citation}

Laurie B. Marczak, Takashi Sakamaki, Shannon L. Turvey, Isabelle Deguise, Sylvia L. R. Wood, and John S. Richardson 2010. Are forested buffers an effective conservation strategy for riparian fauna? An assessment using meta-analysis. Ecological Applications 20:126-134. http://dx.doi.org/10.1890/ 08-2064.1

This Article is brought to you for free and open access by the Biological Sciences at ScholarWorks at University of Montana. It has been accepted for inclusion in Biological Sciences Faculty Publications by an authorized administrator of ScholarWorks at University of Montana. For more information, please contact scholarworks@mso.umt.edu. 


\section{Authors}

Laurie B. Marczak, Takashi Sakamaki, Shannon L. Turvey, Isabelle Deguise, Sylvia L. R. Wood, and John S. Richardson 


\title{
Are forested buffers an effective conservation strategy for riparian fauna? An assessment using meta-analysis
}

\author{
Laurie B. Marczak, ${ }^{1}$ Takashi Sakamaki, Shannon L. Turvey, Isabelle Deguise, Sylvia L. R. Wood, \\ AND JOHN S. RICHARDSON ${ }^{2}$ \\ University of British Columbia, Department of Forest Sciences, 3041-2424 Main Mall, \\ Vancouver, British Columbia V6T 1 Z4 Canada
}

\begin{abstract}
Historically, forested riparian buffers have been created to provide protection for aquatic organisms and aquatic ecosystem functions. Increasingly, new and existing riparian buffers are being used also to meet terrestrial conservation requirements. To test the effectiveness of riparian buffers for conserving terrestrial fauna, we conducted a meta-analysis using published data from 397 comparisons of species abundance in riparian buffers and unharvested (reference) riparian sites. The response of terrestrial species to riparian buffers was not consistent between taxonomic groups; bird and arthropod abundances were significantly greater in buffers relative to unharvested areas, whereas amphibian abundance decreased. Edge-preferring species were more abundant in buffer sites than reference sites, whereas species associated with interior habitat were not significantly different in abundance. The degree of buffer effect on animal abundance was unrelated to buffer width; wider buffers did not result in greater similarity between reference and buffer sites. However, responses to buffer treatment were more variable in buffers $<50 \mathrm{~m}$ wide, a commonly prescribed width in many management plans. Our results indicate that current buffer prescriptions do not maintain most terrestrial organisms in buffer strips at levels comparable to undisturbed sites.
\end{abstract}

Key words: edge effect; forest management; logging; riparian forest buffer; stream habitat; terrestrial conservation.

\section{INTRODUCTION}

River and stream ecosystems and their riparian areas are sensitive to modification of the surrounding landscape by land uses such as urban development, agriculture, and forestry. Over the last several decades, riparian buffers (or reserves) have been employed as a conservation tool in an attempt to maintain natural processes and functions (e.g., sediment interception, nutrient uptake, shading, inputs of large wood, and leaflitter inputs) in running-water ecosystems and consequently protect native aquatic organisms (Naiman et al. 2000, Richardson et al. 2005). Riparian buffers consist of strips of native vegetation alongside rivers and streams, and, similarly, buffers are also used for lakes and wetlands (Hannon et al. 2002, Naiman et al. 2005). Riparian buffers have also been recognized as a potential means of protecting the values of terrestrial riparian areas (FEMAT 1993, Naiman et al. 2005, Sabo et al. 2005). The unique habitat features of riparian areas (access or proximity to water, food, structure, microclimate, and so forth) are essential to support many components of their biodiversity and ecosystem

Manuscript received 6 November 2008; revised 14 May 2009; accepted 15 May 2009. Corresponding Editor: C. Nilsson.

${ }^{1}$ Present address: University of Houston, Department of Biology and Biochemistry, Houston, Texas 77004 USA.

${ }^{2}$ Corresponding author. E-mail: john.richardson@ubc.ca processes (Naiman et al. 2005, Sabo et al. 2005, Richardson and Danehy 2007). Riparian forest and freshwater systems exchange nutritional resources, for example, through processes such as litter and terrestrialinsect inputs into streams, and the export of emergent aquatic insects in riparian forests, which reciprocally enhance the production and biodiversity of both habitats (Nakano and Murakami 2001, Marczak and Richardson 2007). In addition to providing habitat, riparian forests also provide pathways for dispersal of terrestrial organisms and may form a network of dispersal corridors (Naiman et al. 2005).

The high value of riparian areas for terrestrial biodiversity has led some jurisdictions to specifically protect riparian vegetation to broadly conserve both riparian-dependent and riparian-associated species. As part of this focus, buffers have frequently been applied as an umbrella approach for conserving terrestrial species, in contrast to more selective interventions targeting vulnerable species. However, it is still unclear how effective riparian buffer forests are for the conservation of terrestrial animals, and what the optimal buffer design for this purpose is (see Plate 1). Prescribing buffer size or width is one important means by which managers can directly control the value of riparian buffer forests for biological conservation. There are frequently pressures on managers to reduce buffer size in order to maximize the potential for resource 
exploitation, particularly via logging. A buffer width of $\sim 30 \mathrm{~m}$ has become standard in many jurisdictions (where width is defined based on a single side of a stream; Lee et al. 2004). Modifications within the buffer (e.g., selective harvesting) may further alter its value as a conservation measure (Blinn and Kilgore 2001). Additionally, buffers established for the purpose of protecting aquatic resources may not be appropriately designed for the objective of conserving terrestrial organisms. For example, estimates of size requirements of riparian reserves based on conservation of $95 \%$ of existing numbers of various amphibians and reptiles suggest minimal widths of 43-290 m, plus an additional $50 \mathrm{~m}$ as a transitional buffer to ensure microclimates are maintained (Semlitsch and Bodie 2003, Crawford and Semlitsch 2007). In the Pacific Northwest of the United States, requirements for buffer widths on federal lands initially established to protect aquatic resources were doubled to $60 \mathrm{~m}$ to accommodate terrestrial riparian species' requirements (FEMAT 1993). Large variation in guidelines for riparian management exists across jurisdictions, sometimes even for protection of the same species (Blinn and Kilgore 2001, Lee et al. 2004). Frequently the objective of conserving riparian-dependent species is not articulated explicitly by management agencies or the quantitative target for tolerable change is not specified (Richardson and Thompson 2009). Although many studies have experimentally examined effects of riparian buffer forests on various species and higher taxonomic groups of terrestrial animals, e.g., amphibians, mammals, and birds, there has not been a synthesis of these results from which to judge their overall effectiveness.

Using a meta-analysis of published experimental studies, we first tested the hypothesis that riparian buffer forests efficiently conserve riparian fauna by supporting focal taxa at levels close to those present in unharvested riparian forests. Second, we evaluated whether documented edge vs. interior habitat preference might significantly alter the conservation effectiveness of riparian buffer forests for targeted species. Third, we assessed whether wide buffers provide more effective protection of riparian taxa than narrow buffers. Species may continue to be lost with time since the establishment of buffers (lag effects) or alternately evidence of recolonization and recovery may only be evident over longer time scales. We evaluated the evidence for these alternative hypotheses in our data.

\section{Materials And Methods \\ Data selection and extraction}

We used an electronic database (ISI Web of Science) and a search engine (Google Scholar) to identify studies that presented data on terrestrial species abundance within riparian buffers. Within these databases, we searched for the keywords: riparian*, buffer*, strips, and streamside* in combination with biodiversity, terrestrial, logging, clearcut*, abundance, mitigation, and forest*. We restricted our search to papers focusing on animal populations. Studies were included if they met the following criteria: (1) presented mean densities measured as the number of individuals trapped, encountered, or observed per unit area, (2) were conducted in forested landscapes (e.g., buffers in agricultural landscapes were excluded), and (3) contrasted a focal species' density within a riparian buffer against equivalent data for an unharvested, unmanipulated control or reference riparian site. Effect sizes constructed from this contrast can be used to address the question: "Do riparian buffers maintain species in roughly equal densities compared with unmanipulated sites?" We were not able to compare abundances within buffers vs. cleared sites, nor to address community composition changes as there were insufficient studies reporting such values.

Data in selected articles were extracted from the text, tables, or figures. Confidence intervals and standard errors were converted to standard deviations. Data from figures were extracted using GraphClick version 2.9.1 (Arizona Software [2006], unpublished internet freeware), xyExtract (Wilton Pereira da Silva, unpublished internet freeware), or Graph Digitizer Scout 1.21 (ByteScout Software Development 2007). Studies that presented before-after comparisons (or BACI designs) were too scarce to allow the full use of these data. In cases where means were available both before and after the creation of the riparian buffer, we used the "after" data only. When means were presented for more than one species or for multiple years within a single published study, we entered each species and year as an independent estimate in the meta-analysis (Gurevitch and Hedges 1999, Bolnick and Preisser 2005); this occurred most frequently for studies employing birds as focal taxa. Although this method represents a form of pseudoreplication, it substantially increases the flexibility of our analyses; we judged this trade-off to be worthwhile. A complete list of taxa, the studies they were reported in, and their geographic location and calculated effect sizes are presented in the Supplement. Where studies reported ranges instead of values for measurements such as buffer widths or time since buffer establishment (i.e., age of cut-block) we used the mean of these ranges. When a value was reported as a range boundary (greater than or less than a certain value), the reported limiting value was used in further analysis. When data were presented for individual species we further classified these as either expressing a preference for edge or interior habitats based wherever possible on descriptions in the original publications. In many cases we referred to additional published guides or species accounts to establish these designations.

Of 58 published studies that met our a priori criteria, 27 studies had data that were suitable for extraction and subsequent analysis, three of which were from lakes and the remainder from streams. These generated an initial database of 519 comparisons of species abundance or 


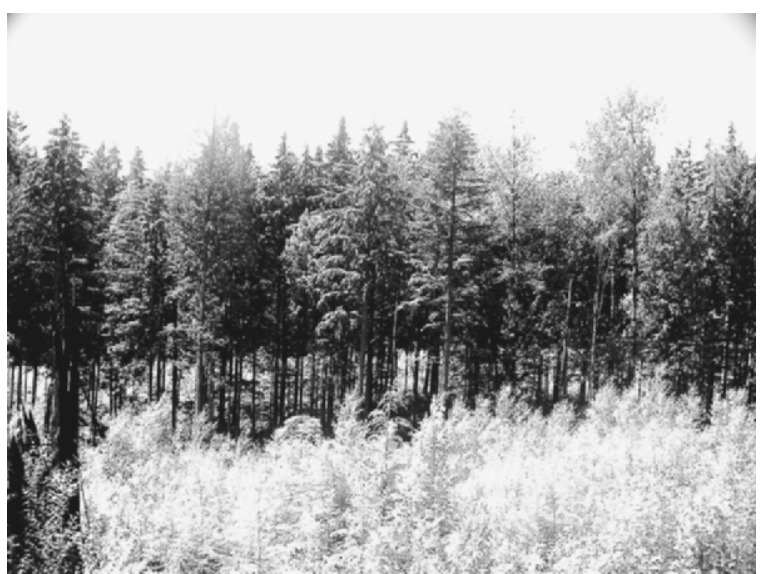

Plate 1. View across a clearcut toward a riparian reserve of 10 meters per side along a small stream in the University of British Columbia's Malcolm Knapp Research Forest, Canada. Photo credit: J. S. Richardson.

density in buffers and reference sites. The majority of studies of terrestrial faunal abundance in riparian buffers that we located focused on birds, small mammals, and amphibians; few studies of invertebrates were located and large mammals and reptiles were not represented.

\section{Effect sizes}

Hedge's $d$, one of the most common effect-size metrics used in meta-analysis, is the difference between the mean of the experimental group (in the present study, means from within riparian buffers) and the mean of the control group (in the present study, means from adjacent or nearby unmanipulated riparian forest) divided by the pooled standard deviation and adjusted for sample size (Rosenberg et al. 2000). Thus in order to determine Hedge's $d$ both variances and means are required. Variance, however, is frequently not reported in ecological studies, particularly in older publications (Adams et al. 1997). Alternative effect-size calculations are available that do not require a measure of variance (e.g., the log response ratio), however these effect sizes cannot be determined when data include 0 values, and are not recommended when these cases are important (Hedges et al. 1999). Accordingly, we used Hedge's $d$ as our measure of effect size. Of the 519 estimates contained in published studies which met our a priori criteria for inclusion we excluded comparisons without a report of variance. However, in some cases we were able to acquire appropriate estimates of variance from the study's authors for further estimates. These resulted in a final data set of 397 comparisons from 17 studies (see Supplement).

Positive values of effect size, $d$, indicate an increase in relative abundance or density in riparian buffers compared to the reference site, whereas a negative effect size indicates a decrease in abundance within buffer sites. Confidence intervals that overlap 0 indicate there is no significant difference between the buffer and reference sites.

\section{Data analysis}

The magnitude of the effect size $d$ was examined to determine whether riparian buffer strips broadly result in increased terrestrial species abundances (significant positive effect size), decreased abundances (significant negative effect size), or are maintaining species in similar levels to those at undisturbed riparian habitats (confidence intervals overlapping 0 ). The homogeneity of effect sizes was tested based on the statistic $Q$; larger $Q$ indicates greater heterogeneity in effect sizes among comparisons (Rosenberg et al. 2000). For both categorical and continuous data analyses, total heterogeneity, $Q_{\mathrm{T}}$, can be partitioned into heterogeneity explained by a model, $Q_{\mathrm{M}}$, and heterogeneity not explained by the model, $Q_{\mathrm{E}}$ (i.e., $Q_{\mathrm{T}}=Q_{\mathrm{M}}+Q_{\mathrm{E}}$ ) (Rosenberg et al. 2000). This partitioning is analogous to that of variation in an analysis of variance. The significance of $Q$ can be tested against a $\chi^{2}$ distribution (Rosenberg et al. 2000).

To explain heterogeneity in taxa response to riparian buffers we divided the data into a number of biologically meaningful classes. For each class, we calculated cumulative mean effect size and confidence intervals around that mean (Rosenberg et al. 2000). These comparisons were made across and within broad taxonomic classes (birds, mammals, amphibians, arthropods, mollusks and lower taxonomic and functional divisions within these groups where data were available), and between species classified as preferring interior habitat or edge habitat. Categorical variables (taxa type, interior or edge preference) were treated as fixed effects.

In addition, we tested the relationship between effect size and riparian-buffer width, and between effect size and length of time since buffer creation using weighted regression analysis (Rosenberg et al. 2000). For these regression analyses we used the absolute value of the effect size so that both positive and negative effect sizes could be incorporated in a single analysis. This approach assesses whether larger effects (whether increases or decreases in taxa abundance) are related to either the width of the riparian buffer or the length of time that a buffer has been established. We chose this approach after first determining that the patterns for negative and positive effects were similar. We used a random-effects model for all investigations of continuous variables. Since the data were strongly grouped by buffer width, and a visual inspection of the data suggested greater variability in narrower buffers, we used Bartlett's test to examine the difference in the variance of effect size between $<50 \mathrm{~m}$ and $>50 \mathrm{~m}$ buffer widths.

We used a visual inspection of normal quantile plots to test for the normal distribution of effect sizes. We tested for evidence of publication bias - where studies 
FIG. 1. Cumulative mean effect size between riparian buffers and paired intact riparian forests, by major taxonomic groupings. Sample sizes are shown in parentheses for each taxon at the bottom of the figure. Error bars are 95\% confidence intervals, CIs; CIs that intersect 0 indicate no significant effect. For mollusks the $95 \%$ CI ranges from -3.480 to 3.873 .

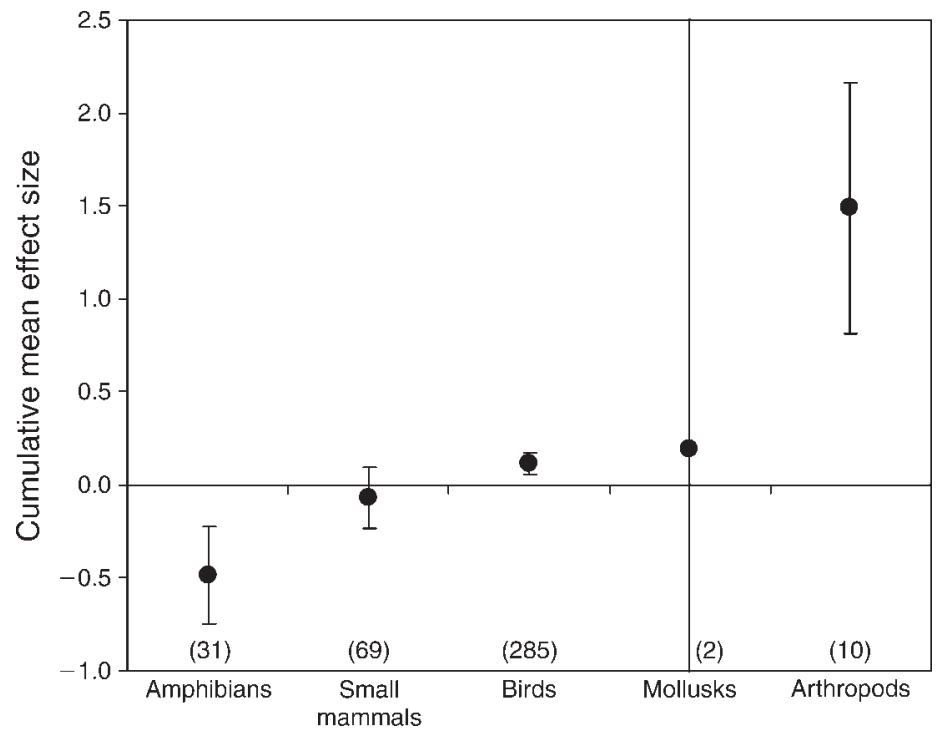

with null effects are less likely to be represented in the published literature-using standard methods (Spearman rank-order correlation; Rosenberg et al. 2000). We used MetaWin version 2.1.5 (Rosenberg et al. 2000) and SAS version 9.1 (SAS Institute 2003) for all statistical procedures.

\section{RESULTS}

Of the 397 estimates of the effect of riparian buffers on abundance and density of terrestrial taxa, birds were the taxon with greatest representation ( $n=285$ studies) followed by small mammals ( $n=69$ studies), amphibians ( $n=31$ studies) and arthropods ( $n=10$ studies). Only two studies were located that presented data on mollusks in a usable format. These data were included in all general investigations of effect size but cannot be used to make inferences about the particular response of mollusks to riparian buffer creation. Visual inspection of a normal-quantile plot and a standard histogram indicated that the data robustly met the assumption of normality. We found no evidence of publication bias $\left(R_{\mathrm{S}}\right.$ $=0.066, P=0.190)$ based on a visual inspection of a funnel plot. The overall cumulative mean effect size was positive (overall higher abundance in buffers compared to unmanipulated riparian forest) and significantly different than 0 (cumulative mean $=0.0785,95 \% \mathrm{CI}=$ 0.023-0.134). Likewise, the magnitude (absolute value) of the effect of riparian buffers on terrestrial faunal abundance also significantly differed from 0 (absolute value of cumulative mean $=0.597,95 \% \mathrm{CI}=0.541-$ 0.652). Total heterogeneity, $Q_{\mathrm{T}}$, within the data was significant indicating that further structure was present in the data $\left(Q_{\mathrm{T}}=804.3, \mathrm{df}=396, P<0.0001\right)$.

The effect of riparian buffers varied by taxa group (heterogeneity of the model $Q_{\mathrm{M}}=46.6$, df $=4, P<$ 0.0001). Cumulative mean effect sizes for both terrestrial arthropods and birds were positive while the cumulative mean effect size for amphibians was negative (Fig. 1). Within amphibians, the anurans ( $n=15$ studies) showed proportionally greater changes (both positive and negative) relative to salamanders ( $n=16$ studies) (absolute value of effect size, $Q_{\mathrm{M}}=6.10$, $\mathrm{df}=1, P=$ 0.014); no other comparison of the effects of buffers within other taxa were significant. The density of small mammals decreased in buffers but this effect was not significant (Fig. 1). The density of mollusks did not differ significantly between riparian buffers and reference sites, but this taxon was represented in only two studies.

For the data including all five taxa groups, taxa identified as edge specialists were present in significantly greater densities in buffers, and also showed significantly higher cumulative mean effect sizes than interior species ( $Q_{\mathrm{M}}=8.87$, df $=1, P=0.003$; Fig. 2a). Within birds, cumulative mean effect size varied according to edge and interior specialists, and edge specialists showed positive cumulative mean effect sizes, indicating their higher abundance in buffer sites $\left(Q_{\mathrm{M}}=4.32, \mathrm{df}=1, P=0.038\right.$; Fig. 2b). For small mammals, there was no significant difference for either edge or interior specialists $\left(Q_{\mathrm{M}}=\right.$ 0.94, df $=1, P=0.332$; Fig. 2c).

There was no relationship between buffer width and the magnitude of the difference in overall taxa abundance between riparian buffers and reference sites $\left(Q_{\mathrm{M}}=\right.$ 0.87 , df $=1, P=0.351$; Fig. 3a). Effect sizes associated with buffers $<50 \mathrm{~m}$ in width were significantly more variable than effect sizes for buffers $>50 \mathrm{~m}$ (Bartlett's test: $\chi^{2}=3.96$, df $\left.=1, P=0.047\right)$. There was no relationship between the time since buffer establishment (or forest harvesting) and the magnitude of the difference in taxa abundance between riparian buffers and reference sites $\left(Q_{\mathrm{M}}=1.02\right.$, df $=1, P=0.313$; Fig. 3b). 

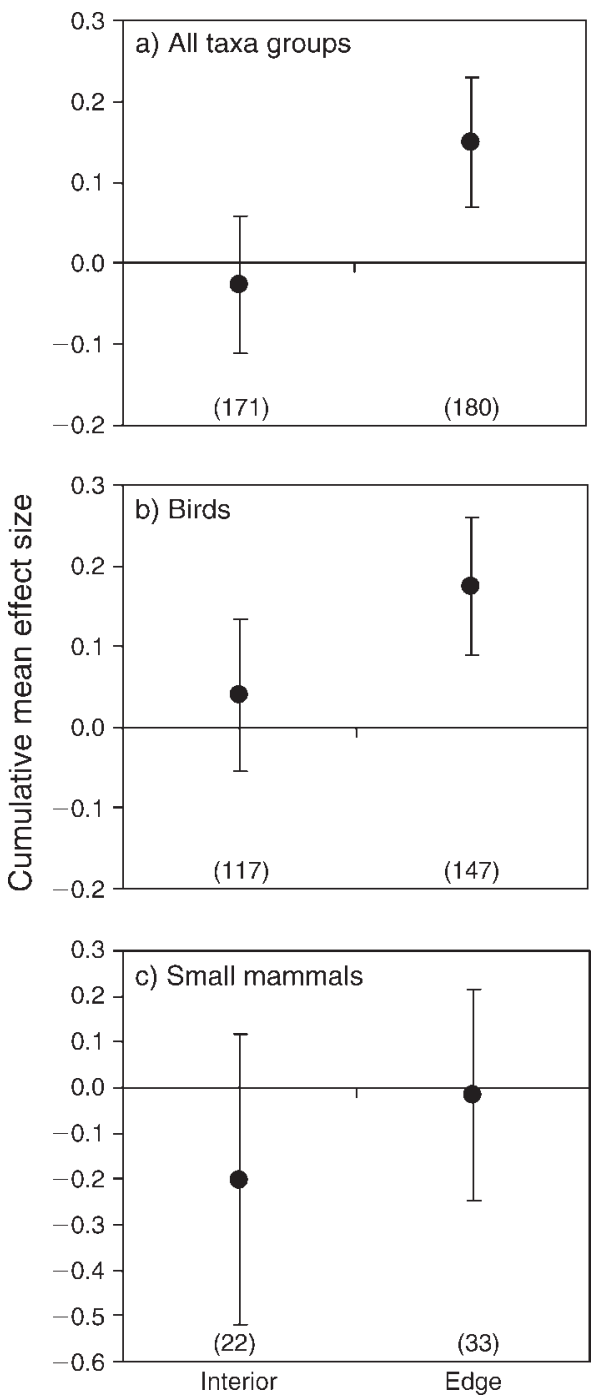

FIG. 2. Difference between cumulative mean effect size for riparian species identified as preferring interior habitats and edge habitats for (a) all the taxa groups, (b) birds, and (c) small mammals. Sample sizes are shown in parentheses for each grouping at the bottom of each panel. Error bars are 95\% confidence intervals; CIs that intersect 0 indicate no significant effect.

\section{Discussion}

The question of whether terrestrial taxa can be maintained in riparian buffers at levels similar to unmanipulated sites must be addressed to determine the effectiveness of buffers as a conservation tool for riparian-associated species. Overall, our analysis determined that differences in the abundance of target terrestrial taxa between riparian buffers and undisturbed riparian forests included in this meta-analysis are small, indicating that the coarse-filter approach of using riparian buffers as an ad hoc conservation measure for multiple terrestrial taxa appears, at first glance, to be working. However, our results suggest that the response to buffers strongly differs between species, even within a single animal group (e.g., amphibians).

\section{Taxon-specific responses}

The overall effect size for birds was positive indicating that, as a group, birds are more abundant in riparian buffer strips than in associated undisturbed riparian forests. In general, there are two possible explanations for increased numbers of birds in riparian-forest buffers (Hanowski et al. 2003). First, birds could be displaced by harvest in upland areas and move to remaining riparian-buffer habitat, potentially resulting in temporarily increased bird populations in riparian forests or buffers ("packing"). Second, riparian buffers could provide edge species with preferred habitats and augment their populations. The positive responses of edge-associated bird species in our results support the second explanation, i.e., the increase in overall bird populations within riparian buffers is being driven by an increased abundance of edge species. The edges of riparian buffer strips may provide high-quality feeding habitat (high prey abundance, good perches) for aerialforaging and foliage-gleaning insectivorous birds that are not restricted to habitat types missing from relatively
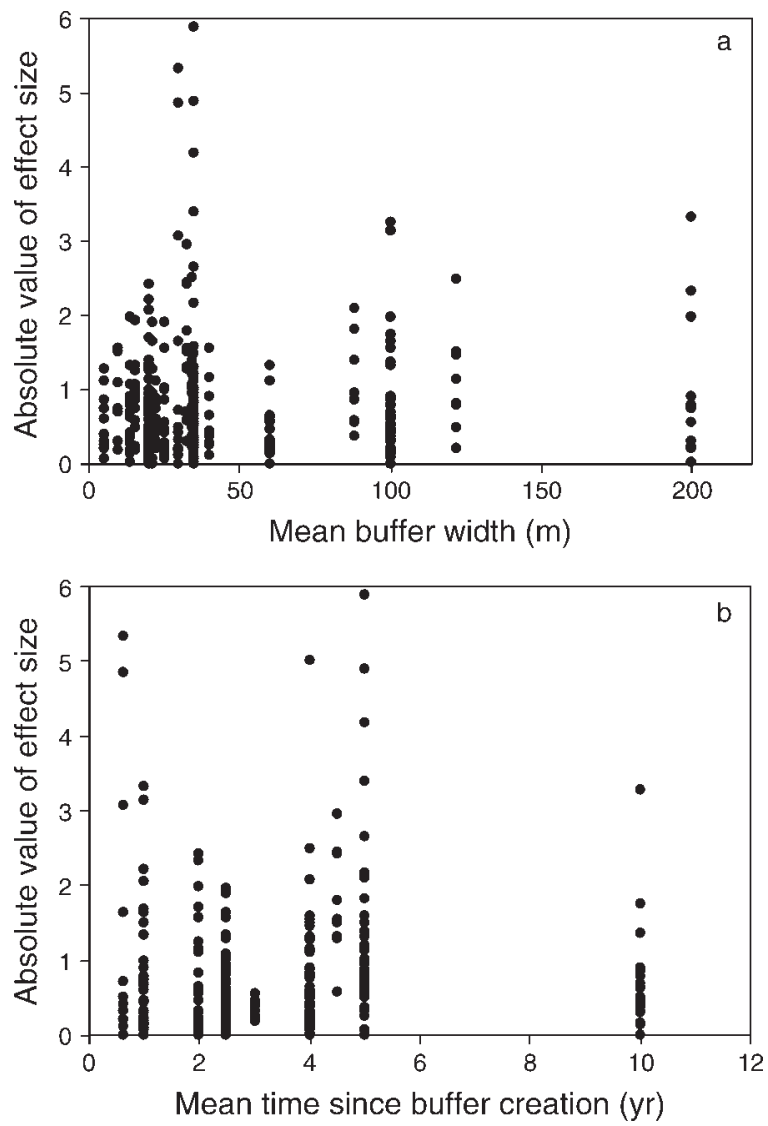

FIG. 3. Distribution of the absolute value of effect size (a) against mean buffer width and (b) against mean time since the buffer was created. 
narrow buffer strips (e.g., interior forest) (Whitaker et al. 2000, Laurance 2004). Other insectivorous species such as bats (Chiroptera), spiders (Arachnida), and dragonflies (Odonata), which forage heavily on localized concentrations of flying insects at forest edges, may also treat buffer strips as high-quality habitat patches. In this meta-analysis we demonstrated both a generalized increase in density of bird populations (particularly edge-associated species) and an increase in density of aerial insect populations in riparian buffer strips.

Forest-dependent (i.e., interior-habitat-preferring) birds respond differently to riparian buffer treatments than edge-preferring species. Whereas riparian buffers provide edge-dwelling birds with ecologically favorable conditions and can increase entire bird populations in riparian areas at least temporarily, riparian buffer treatments are also known to result in declines in some forest-dependent bird species (Darveau et al. 1995, Hannon et al. 2002). The mechanisms for this are various: buffer treatments may alter the position and shape of an individual's territory in a riparian area (Lambert and Hannon 2000); or the cut edge of riparian buffers may negatively affect breeding in riparian areas due to an increased risk of predation (Darveau et al. 1997, Flaspholer et al. 2001), brood parasitism (Donovan et al. 1995, Robinson et al. 1995), or altered vegetation (Lambert and Hannon 2000). The overall positive response of bird taxa to riparian forests may be an ephemeral phenomenon as new edge species enter the buffer immediately following its creation before other species are lost. There is likely a lag time after buffer creation before interior-dependent and other species are lost due to habitat loss or degradation; with greater time since buffer establishment, interior bird species may be lost from these habitats. Whether regeneration in the adjacent harvested zones can be quick enough to compensate for lost habitat remains to be seen.

Our results also suggest that many riparian buffer treatments did not provide environments sufficient to maintain amphibian abundance in riparian areas, resulting in overall decreases in amphibian abundance in riparian buffer strips. Amphibians are known to be moderately mobile and can migrate distances of kilometers from stream to upland habitats (Johnston and Frid 2002, MacDonald et al. 2006). However, amphibian life cycles are more strongly dependent on water than those of other taxa, such as most mammals or birds. Numerous studies have demonstrated that, within the range of buffer widths typical in operational forest management, microclimate in the riparian buffer (including temperature, humidity, and soil moisture) is significantly different from undisturbed forest, resulting in strong edge effects (Brosofske et al. 1997, Stewart and Mallik 2006). Narrow buffer zones also permit changes to stream environmental conditions (e.g., light and temperature) relative to streams surrounded by continuous forest (Kiffney et al. 2003, Moore et al. 2005). Inputs of fine sediment and increased water tempera- tures in streams adjacent to riparian-buffer sites can negatively affect amphibian abundance (Welsh and Ollivier 1998). Many buffer treatments may not sufficiently preserve riparian-forest microclimate and/or aquatic conditions for maintenance of amphibian abundance (Vesely and McComb 2002).

At first glance, riparian buffers appear to provide adequate protection for small mammals, since smallmammal abundance did not differ significantly between buffer and reference sites. However, these results do not account for the species-specific responses to riparian buffers. The habitat associations and response to disturbance of small mammals are strongly variable by species (Darveau et al. 2001, Cockle and Richardson 2003, Macdonald et al. 2006). While it is possible that existing riparian buffers are sufficient to maintain smallmammal communities similar to those at reference sites, it is also possible that community composition is significantly altered within buffers. Given the wide degree of variability of response to buffer treatments across the small-mammal species included in this analysis, it seems more likely that the lack of a significant difference between small-mammal abundance at buffer and reference sites reflects an averaging of positive and negative effects.

\section{How wide should buffer strips be to conserve terrestrial fauna?}

Many previous studies of single taxa (including many that were included in this meta-analysis) have concluded that narrow buffers do not adequately maintain terrestrial fauna, especially interior-forest species (Darveau et al. 1995, Semlitsch and Bodie 2003). Hannon et al. (2002) concluded that 20-m-wide buffers will not conserve songbirds and that even 200-m-wide buffer strips are not capable of sustaining populations of largebodied avian taxa. Positive relationships have been observed between taxa abundance and buffer width (Hannon et al. 2002, Hanowski et al. 2003, Shirley and Smith 2005), and wider buffers than are the management norm are generally promoted within the scientific literature. Keller et al. (1993) suggested that a 100-m buffer was required to protect eastern deciduous riparian forest function; Lambert and Hannon (2000) determined that a 100-200 m buffer was necessary to maintain populations of target bird species. Similarly large buffer sizes (150-175 m) have been suggested as necessary to support populations of $90 \%$ of songbirds in the Coastal Montane habitats of British Columbia (Shirley and Smith 2005). These common findings led us to anticipate that the magnitude of the difference between buffers and reference sites would be moderated by increasing buffer widths. This pattern was not present in the data while a test of the variance in effect sizes associated with buffers greater and less than $50 \mathrm{~m}$ (a commonly prescribed width in many management plans; Lee et al. 2004) demonstrated that narrow buffers are associated with greater variability in effect sizes. This 
variability is composed of both large positive and large negative effects. The high degree of variability associated with these smaller buffers suggests that current buffer prescriptions are insufficient to maintain terrestrial organisms at levels comparable to undisturbed sites, if that is the management target (Richardson and Thompson 2009).

\section{Are we examining temporary trends or long-term patterns?}

Results from all studies were short term $(<10$ years following forest harvesting) and should be viewed with caution. The absence of a significant relationship between buffer age and effect size may reflect the short time scales represented by the studies included in this meta-analysis, during which animals may respond similarly to both narrow and wide buffers. Changes in forest structure will inevitably occur in these riparian buffers over time; yet corresponding shifts in the abundance of species as a consequence of these changes may not be detectable over the short time spans of most studies. Some temporal variability is inherent to the focal species being studied, e.g., cyclic populations of small mammals. The short time spans of the studies included also do not account for stochastic events such as floods, droughts, fire, windthrow, nor for the potential time lags in species losses. Small, remnant populations in riparian buffers may be more vulnerable to demographic and environmental stochasticity than populations in continuous habitat. In contrast, longer study periods might also reveal the regaining of predisturbance population sizes over time. This could occur through recolonization by species initially lost from the system (via environmental change associated with succession) or slower adaptations to the changed environment (e.g., development of sun leaves in plants). Furthermore, interactions between animals, such as competition for resources and predation, potentially complicate the effects of riparian buffer treatment for animals living in buffers. For instance, Fredericksen and Fredericksen (2004) showed an increase in arthropod abundance in gaps and thus a potential increase in food sources for various kinds of animals. Buffer treatments could trigger shifts in community composition over time. These potential, persistent changes associated with buffer-treatment effects are well beyond the study period of any of the papers included in this meta-analysis.

Edge effects from adjacent cutblocks can penetrate as much as $40 \mathrm{~m}$ into buffers (Brosofske et al. 1997), resulting in more open canopy, greater risk of blowdown, larger quantities of downed wood, and other structural forest changes (Harper and Macdonald 2001, Hannon et al. 2002). Even with rapid regeneration times, these edge effects can continue to influence forest structure and composition for upwards of 15 years (Harper and Macdonald 2001). The effective size of buffer strips for species with strong interior habitat or old-growth forest requirements may decrease over time, or, conversely, increases in the shrub layer at edges may provide more habitat for some species. Although not considered here, the landscape context (matrix habitat), i.e., what is beyond the riparian reserve, can also be an important determinant for the value of riparian reserves for some species (Lambert and Hannon 2000, Hannon et al. 2002, Martin et al. 2006). The availability of alternative environments outside the buffer (e.g., breeding sites for amphibians or foraging areas for various species), can affect the value of nearby remnant riparian forest. As most of the taxa considered in our analyses have high mobility and can migrate out of riparian areas, the landscape context of riparian reserves undoubtedly deserves further evaluation.

\section{Conclusions: are buffer strips appropriate conservation tools for terrestrial fauna?}

Management agencies rarely differentiate in their plans or evaluations between supporting organisms in buffers at their original abundance and simply maintaining the presence of a species (Richardson and Thompson 2009). Our results show that the approach of using buffer strips or zones around aquatic features as a management strategy for the conservation of terrestrial taxa may not be as effective as commonly assumed. The variability of responses by different taxa to buffers as narrow as $5 \mathrm{~m}$ and as wide as $200 \mathrm{~m}$ illustrates that riparian buffers alone cannot be relied on to provide the same conservation value for all terrestrial taxa. In particular, riparian buffers maintain only certain taxa at levels comparable to unharvested areas; many taxa increase significantly (edge-preferring species in particular), while others decline. This suggests that the longerterm community dynamics in riparian buffers may be substantially different from undisturbed areas.

As a coarse-filter approach, riparian buffers may provide some incidental protection for terrestrial species, however, it appears unlikely that currently prescribed buffer widths (generally 5-50 m) will provide sufficient habitat beyond the requirements of the most common or tolerant species. At the same time, the approach of lobbying for increases in the standard width of riparian buffers will also likely prove insufficient to adequately conserve riparian fauna. Recent approaches have included calls for targeted protection of sensitive habitats (Olsen et al. 2007) or establishing wildlife tree patches for particular focal species (Spies et al. 2007) rather than seeking limited protection everywhere. This approach has the benefit of establishing greater protections in particularly sensitive habitats (e.g., headwaters) while not demanding infeasible removals of habitat from the productive land base. Although buffers have also been shown to promote landscape connectivity and may be used as movement corridors by some species (Doherty and Grubb 2002, Renöfält et al. 2005), the results of our quantitative synthesis suggest that buffer strips as currently employed should not be viewed as a sufficient strategy for maintaining interior-habitat-pre- 
ferring riparian fauna, particularly amphibians. Substantially wider buffers that incorporate areas of upland forest in addition to riparian-zone vegetation may be required to supply an adequate terrestrial conservation function for certain sensitive species (Semlitsch and Bodie 2003); these enhanced protections will need to be balanced by identifying areas where partial resource extraction within reserves is feasible.

\section{AcKnowledgments}

This manuscript was substantially improved by the careful commentary of several anonymous reviewers. We thank A. Reiss and M. Hogg for assistance with data extraction. We acknowledge A. Mallik, S. Shirley, J. Hanowski, M. Raphael, E. Cole, and M. Darveau for graciously providing us with unpublished data. The Forest Sciences Program (British Columbia) provided financial support.

\section{Literature Cited}

Adams, D. C., J. Gurevitch, and M. S. Rosenberg. 1997. Resampling tests for meta-analysis of ecological data. Ecology 78:1277-1283.

Blinn, C. R., and M. A. Kilgore. 2001. Riparian management practices: a summary of state guidelines. Journal of Forestry 99:11-17.

Bolnick, D. R., and E. L. Preisser. 2005. Resource competition modifies the strength of trait-mediated predator-prey interactions: a meta-analysis. Ecology 86:2771-2779.

Brosofske, K. D., J. Q. Chen, R. J. Naiman, and J. F. Franklin. 1997. Harvesting effects on microclimatic gradients from small streams to uplands in western Washington. Ecological Applications 7:1188-1200.

Cockle, K. L., and J. S. Richardson. 2003. Do riparian buffer strips mitigate the impact of clearcutting on small mammals? Biological Conservation 113:133-140.

Crawford, J. A., and R. D. Semlitsch. 2007. Estimation of core terrestrial habitat for stream-breeding salamanders and delineation of riparian buffers for protection of biodiversity. Conservation Biology 21:152-158.

Darveau, M., P. Beauchesne, L. Bélanger, J. Huot, and P. Larue. 1995. Riparian forest strips as habitat for breeding birds in boreal forest. Journal of Wildlife Management 59: 67-78.

Darveau, M., L. Bélanger, J. Huot, E. Mélançon, and S. DeBellefeuille. 1997. Forestry practices and the risk of bird nest predation in a boreal coniferous forest. Ecological Applications 7:572-580

Darveau, M., P. Labbé, P. Beauchesne, L. Bélanger, and J. Huot. 2001. The use of riparian forest strips by small mammals in a boreal balsam fir forest. Forest Ecology and Management 143:95-104.

Doherty, P. F., and T. C. Grubb. 2002. Survivorship of permanent-resident birds in a fragmented forested landscape. Ecology 83:844-857.

Donovan, T. M., F. R. Thompson III, J. Faaborg, and J. R. Probst. 1995. Reproductive success of migratory birds in habitat sources and sinks. Conservation Biology 9:13801395.

Flaspholer, D. J., S. A. Temple, and R. N. Rosenfield. 2001. Species-specific edge effects on nest success and breeding bird density in a forested landscape. Ecological Applications 11: 32-46.

Forest Ecosystem Management Assessment Team [FEMAT]. 1993. Forest ecosystem management: an ecological, economic, and social assessment. United States Forest Service, United States Department of Commerce, National Oceanic and Atmospheric Administration, National Marine Fisheries Service, United States Bureau of Land Management, Fish and Wildlife Service, Portland, Oregon, USA.
Fredericksen, N. J., and T. S. Fredericksen. 2004. Impacts of selective logging on amphibians in a Bolivian tropical humid forest. Forest Ecology and Management 191:275-282.

Gurevitch, J., and L. V. Hedges. 1999. Statistical issues in ecological meta-analyses. Ecology 80:1142-1149.

Hannon, S. J., C. A. Paszkowski, S. Boutin, J. DeGroot, S. E. MacDonald, M. Wheatley, and B. R. Eaton. 2002. Abundance and species composition of amphibians, small mammals, and songbirds in riparian forest buffer strips of varying widths in the boreal mixedwood of Alberta. Canadian Journal of Forest Research 32:1784-1800.

Hanowski, J., N. Danz, J. Lind, and G. Niemi. 2003. Breeding bird response to riparian forest harvest and harvest equipment. Forest Ecology and Management 174:315-328.

Harper, K. A., and S. E. Macdonald. 2001. Structure and composition of riparian boreal forest: new methods for analyzing edge influence. Ecology 82:649-659.

Hedges, L. V., J. Gurevitch, and P. S. Curtis. 1999. The metaanalysis of response ratios in experimental ecology. Ecology 80:1150-1156.

Johnston, B., and L. Frid. 2002. Clearcut logging restricts the movements of terrestrial Pacific giant salamanders (Dicamptodon tenebrosus Good). Canadian Journal of Zoology 80: 2170-2177.

Keller, C. M. E., C. S. Robbins, and J. S. Hatfield. 1993. Avian communities in riparian forests of different widths in Maryland and Delaware. Wetlands 13:137-144.

Kiffney, P. M., J. S. Richardson, and J. P. Bull. 2003. Responses of periphyton and insects to experimental manipulation of riparian buffer width along forest streams. Journal of Applied Ecology 40:1060-1076.

Lambert, J. D., and S. J. Hannon. 2000. Short-term effects of timber harvest on abundance territory characteristics, and pairing success of Ovenbirds in riparian buffer strips. Auk 117:687-698.

Laurance, S. G. W. 2004. Responses of understory rain forest birds to road edges in central Amazonia. Ecological Applications 14:1344-1357.

Lee, P., C. Smyth, and S. Boutin. 2004. Quantitative review of riparian buffer width guidelines from Canada and the United States. Journal of Environmental Management 70:165-180.

Macdonald, S. E., B. Eaton, C. S. Machtans, C. Paszkowski, S. Hannon, and S. Boutin. 2006. Is forest close to lakes ecologically unique? Analysis of vegetation, small mammals, amphibians and songbirds. Forest Ecology and Management 223:1-17.

Marczak, L. B., and J. S. Richardson. 2007. Spiders and subsidies: results from the riparian zone of a coastal temperate rainforest. Journal of Animal Ecology 76:687-694.

Martin, T. G., S. McIntyre, C. P. Catterall, and H. P. Possingham. 2006. Is landscape context important for riparian conservation? Birds in grassy woodlands. Biological Conservation 127:201-214.

Moore, R. D., D. L. Spittlehouse, and A. Story. 2005. Riparian microclimate and stream temperature response to forest harvesting: a review. Journal of the American Water Resources Association 41:813-834.

Naiman, R. J., R. E. Bilby, and P. Bisson. 2000. Riparian ecology and management in the Pacific coastal rain forest. BioScience 50:996-1011.

Naiman, R. J., H. Décamps, and M. E. McClain. 2005. Riparia: ecology, conservation, and management of streamside communities. Elsevier Academic Press, San Diego, California, USA.

Nakano, S., and M. Murakami. 2001. Reciprocal subsidies: dynamic interdependence between terrestrial and aquatic food webs. Proceedings of the National Academy of Sciences (USA) 98:166-170.

Olsen, D. H., P. Anderson, C. A. Frissell, H. H. Welsh, Jr., and D. F. Bradford. 2007. Biodiversity management approaches for stream-riparian areas: perspectives for Pacific Northwest 
headwater forests, microclimates and amphibians. Forest Ecology and Management 246:81-107.

Renöfält, B. M., R. Jansson, and C. Nilsson. 2005. Spatial patterns of plant invasiveness in a riparian corridor. Landscape Ecology 20:165-176.

Richardson, J. S., and R. J. Danehy. 2007. A synthesis of the ecology of headwater streams and their riparian zones in temperate forests. Forest Science 53:131-147.

Richardson, J. S., R. J. Naiman, F. J. Swanson, and D. E. Hibbs. 2005. Riparian communities associated with Pacific Northwest headwater streams: assemblages, processes, and uniqueness. Journal of the American Water Resources Association 41:935-947.

Richardson, J. S., and R. M. Thompson. 2009. Setting conservation targets for freshwater ecosystems in forested catchments. Pages 244-263 in M.-A. Villard and B.-G. Jonsson, editors. Setting conservation targets for managed forest landscapes. Cambridge University Press, Cambridge, UK.

Robinson, S. K., F. R. Thompson III, T. M. Donovan, D. R. Whitehead, and J. Faaborg. 1995. Regional forest fragmentation and the nesting success of migratory birds. Science 267: 1987-1990.

Rosenberg, M. S., D. C. Adams, and J. Gurevitch. 2000. MetaWin statistical software for meta-analysis version 2 . Sinauer Associates, Sunderland, Massachusetts, USA.

Sabo, J. L., R. Sponseller, M. Dixon, K. Gade, T. Harms, J. Heffernan, A. Jani, G. Katz, C. Soykan, J. Watts, and J. Welter. 2005. Riparian zones increase regional species richness by harboring different, not more, species. Ecology 86:56-62.

SAS Institute. 2003. SAS version 9.1. SAS Institute, Cary, North Carolina, USA.

Semlitsch, R. D., and J. R. Bodie. 2003. Biological criteria for buffer zones around wetlands and riparian habitats for amphibians and reptiles. Conservation Biology 17:12191228.

Shirley, S. M., and J. N. M. Smith. 2005. Bird community structure across riparian buffer strips of varying width in a coastal temperate forest. Biological Conservation 125:475489.

Spies, T. A., B. C. McComb, R. S. H. Kennedy, M. T. McGrath, K. Olsen, and R. J. Pabst. 2007. Potential effects of forest policies on terrestrial biodiversity in a multiownership province. Ecological Applications 17:48-65.

Stewart, K. J., and A. U. Mallik. 2006. Bryophyte responses to microclimatic edge effects across riparian buffers. Ecological Applications 16:1474-1486.

Vesely, D. G., and W. C. McComb. 2002. Salamander abundance and amphibian species richness in riparian buffer strips in the Oregon Coast Range. Forest Science 48:291-297.

Welsh, H. H., Jr., and L. M. Ollivier. 1998. Stream amphibians as indicators of ecosystem stress; a case study from California's redwoods. Ecological Applications 8:1118-1132.

Whitaker, D. M., A. L. Carroll, and W. A. Montevecchi. 2000. Elevated numbers of flying insects and insectivorous birds in riparian buffer strips. Canadian Journal of Zoology 78:740747.

\section{SUPPLEMENT}

An ASCII text file listing the studies included in the meta-analysis including treatment and reference means, SDs, and calculated effect sizes (Ecological Archives A020-003-S1). 